\title{
MITIGATION OF $\mathrm{CaCO}_{3}$ SCALE FORMATION IN PIPES UNDER INFLUENCE OF VIBRATION AND ADDITIVES
}

\author{
W. Mangestiyono ${ }^{1}$, S. Muryanto ${ }^{2}$, J. Jamari ${ }^{3}$ and A.P. Bayuseno ${ }^{3 *}$ \\ ${ }^{1}$ Mechanical Engineering, School of Vocation, Diponegoro University, 50275, Indonesia \\ ${ }^{2}$ Department of Chemical Engineering, UNTAG University in Semarang, 50232, Indonesia \\ ${ }^{3}$ Department of Mechanical Engineering, Diponegoro University, 50275, Indonesia \\ *E-mail :apbayuseno@gmail.com
}

\begin{abstract}
This study aims to mitigate $\mathrm{CaCO}_{3}$ scale formation in pipes under influence of vibration and oxalic and formic acid additives. The vibration of the pipes was generated mechanically by an electrical motor and controlled by a computer program. $\mathrm{CaCO}_{3}$ scale was synthesized by $\mathrm{CaCl}_{2}$ and $\mathrm{Na}_{2} \mathrm{CO}_{3}$ reagents. The scale deposition was examined at a temperature of $35^{\circ} \mathrm{C}$ and vibration frequencies of $0.00,3.00$, and $6.00 \mathrm{~Hz}$. The mass of scale deposit was found as $3.3211 \mathrm{~g}, 3.8358 \mathrm{~g}$, and $4.4705 \mathrm{~g}$. Fourier Transform Infra Red spectroscopy analysis proved that the additives successfully diffused into the crystal lattice and retarded carbonate anion formation, which consequently retarded the scale formation. In addition, the use of oxalic acid made the morphology of vaterite-changed. However,the formic acid was added, a new habit of hexagonal thin-plate vaterite-could be observed and a fewer carbonate scale was obtained.
\end{abstract}

Keywords: $\mathrm{CaCO}_{3}$, diffusion, formic acid, oxalic acid, vibration, morphology

(C) RASĀYAN. All rights reserved

\section{INTRODUCTION}

Calcium carbonate is the predominant scale forming in industrial piping systems besides other minerals such as calcium and barium sulfates, which in most cases reduces flow rate, decreases overall heat transfer coefficient, and leads to unscheduled equipment shutdown $n^{1-5}$. In the last decade, many researchers have attempted to prevent the formation of calcium carbonate scales through laboratory research. Early studies on control of calcium carbonate scales focused on the kinetics; however, later studies have explored the effects of external factors, considering temperature and flow rate on its formation ${ }^{6}$. More external factors prevalent in industries, such as the electromagnetic field and mechanical vibration, may potentially affect scaling process ${ }^{7-10}$. In the present study, temperature,vibration and additives are considered as external factors and investigated through appropriate methods.Vibration in the piping system can be determined as internal and external factors, where the internal factor is the vibration generated by fluid flow, which can also be called fluid-induced vibration ${ }^{11-13}$. The external factor exists because the vibration is influenced by external excitation caused by the operation of many mechanical equipment such as an electric pump, blower, extruder, compressor, diesel engine, and turbine ${ }^{14,15}$. The presence or absence of these factors influences the formation of scales inside pipe surfaces. For a certain condition, internal and external factors can simultaneously vibrate piping system and produce some forces that can be used for mitigating fouling.

Many factors involved in the vibration mechanism have been suggested to affect scale formation. For example, vibration generates mechanical force to the solution, which is known as hydrodynamic force, and it is suspected to promote the scaling process. Quddus and Hadhrami observed that the elevated hydrodynamic force resulted in the increase of $\mathrm{CaCO}_{3}$ scale deposition ${ }^{16}$. Even though the hydrodynamic force in their study was generated in a different way, the effects may not be much different. Furthermore, persistent vibration makes the solution to respond in the vibration direction. Under a vibration frequency of $6.00 \mathrm{~Hz}$, the solution acts as much as 720 times per minute in response; in addition, the diffusion-

Rasayan J. Chem., 12(1), 192-204(2019)

http://dx.doi.org/10.31788/RJC.2019.1215055

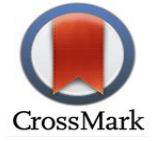


controlled reaction occurs in the solution. A scaling process in such mechanism takes place in a specific manner and typically occurs in almost all industries. Therefore, an appropriate method must be utilized to establish an approach as close as possible to the real process in industries.

In this research, to prevent scale deposition, the separate use of two additives, which are constituents of the carboxylic acid family was considered, i.e., oxalic acid $\left(\mathrm{C}_{2} \mathrm{H}_{2} \mathrm{O}_{4}\right)$ and formic acid $\left(\mathrm{CH}_{2} \mathrm{O}_{2}\right)$. Wada outlined the mechanism of utilizing carboxylic acid in preventing $\mathrm{CaCO}_{3}$ scales. According to Wada, the nucleation was not influenced by the presence of carboxylic acids, but crystal growth was reduced by acid adsorption to the surface ${ }^{17}$. Ersen also outlined the mechanism of acid adsorption. Initially, acid is ionized to form carboxylate and then changes to calcium ions. As the dimension of acid ions is larger, the lattice is covered up by those ions and distorts the crystals; therefore, crystal growth is retarded ${ }^{18}$. Based on such mechanism, the long-chain acids such as ethylenediaminetetraacetic acid,palmitic acid, and poly (citric acid) may be the best choice to retard the crystal growth because of their capability to cover up the lattice. However, in the current research, the authors try a different mechanism, that called diffusion, to prevent the scale formation.

Many researchers have studied the inhibition process mechanism. Tzoti pointed out that the scale retardation mechanism is a threshold effect, a crystal distortion effect, dispersion, and chelation ${ }^{19}$. Mutairi outlined the scale inhibition mechanism as follows: the destruction of the scale activity, changes in the physical interaction between the foulant and the surface, forced scale removal, and fouling potential modification $^{20}$. He stated the mechanism is selective nucleation, makeup adsorption resistance, and change in the crystal surface to enhance agglomeration tendency ${ }^{21}$. Among all mechanisms, the dispersion is closest to the proposed diffusion mechanism, which allows inhibitor ions to diffuse in the lattice so that their morphology is somehow changed.

Diffusion has been categorized into two: vacancy diffusion and interstitial diffusion ${ }^{22}$. Vacancy diffusion is a mechanism that involves the interchange of atoms or ions from a normal lattice position to an adjacent vacant lattice site. Interstitial diffusion involves atoms or ions that migrate from an interstitial position to a neighboring vacant one. The mechanism is found in the interdiffusion of impurities such as hydrogen, carbon, nitrogen, and oxygen, which have atoms or ions small enough to fit into the interstitial positions. Therefore, scale inhibition using such a mechanism requires a short-chain and lightweight antiscalant reagent. The selected oxalic acid and formic acid, which belong to the short-chain carboxylic acid family, are appropriate.

Their low densities, which are $1.653 \mathrm{~g} . \mathrm{cm}^{-3}$ and $1.22 \mathrm{~g} . \mathrm{cm}^{-3}$ for oxalic and formic acid, respectively, may increase their interstitial diffusion capabilities. The vibration employed in this research that contributed hydrodynamic forces to the solution may also be able to enhance the energy, which needed for better diffusion $^{22}$.To estimate the diffusion probability, first, the dimension of the ion to be diffuse in this experiment is examined, if suitable or not. Formic acid has only five atoms and a shorter structure of the carboxylic family. In the solution in which the vibration intensively resulted in hydrodynamic force, the formic acid ionic bonding has the potential to break out and crack to become shorter. Koch indicated that that formic acid can be decomposed to $\mathrm{CO}$ ion and $\mathrm{H} 2 \mathrm{O}$ in the presence of heat ${ }^{23}$. On the other hand, the radius of the hydrogen atom $(0.35 \AA)$ and carbon $(0.76 \AA)$ may be reduced when the atom is ionized in the solution because the electrons are modified 24 .

The dimension of vaterite lattice is known as $a=12.170 \AA$; $b=7.12 \AA$ and $c=25.32 \AA 25$. As has been calculated, lattice geometry of vaterite has a mean volume of $2,194 \AA 3$, while hydrogen volume is 0.96 $\AA 3$; thus, one lattice of vaterite could be filled by 2,285 atoms hydrogen. Therefore, it can be deduced that the diffusion of formic acid or part of formic acid to the lattice is possible. Between the two diffusion mechanisms, interstitial diffusion is more possible because the diffused atom dimension has a low magnitude ${ }^{22}$.

The current research was carried out to examine the influence of temperature, mechanical vibration, and additives on $\mathrm{CaCO}_{3}$ scale formation in vibrating piping systems, and it was performed on a laboratory scale. An appropriate experimental based laboratory method as close as possible to the real process in industries was prepared. To examine the diffusion mechanism, analytical based laboratory methods such as differential scanning calorimetry (DSC), scanning electron microscopy (SEM), X-ray diffractometry (XRD), and Fourier transform Infrared (FTIR) spectroscopy were used for data analysis. 
RASĀYAN J. Chem.

Vol. 12 | No. 1 |192 - 204| January - March | 2019

\section{EXPERIMENTAL}

\section{Material and Methods}

$\mathrm{CaCO}_{3}$ precipitation was synthesized by mixing $\mathrm{CaCl}_{2}$ and $\mathrm{Na}_{2} \mathrm{CO}_{3}$ solution purchased from Merck ${ }^{\circledR}$ according to the reaction in eq. (1).

$$
\mathrm{CaCl}_{2(\mathrm{aq})}+\mathrm{Na}_{2} \mathrm{CO}_{3(\mathrm{aq})} \rightarrow \mathrm{CaCO}_{3(\mathrm{~s})}+2 \mathrm{NaCl}_{(\mathrm{aq})}
$$

Calcium concentration in the solution was determined as $3,500 \mathrm{ppm}$, and carbonate concentration was set as its stoichiometry. Calcium concentration in $3,500 \mathrm{ppm}$ was considered as a proper concentration required to point out the influence of temperature, vibration, and inhibitor on scale deposition. The magnitude may be too high if the experiment is conducted in a baker or batch crystallizer, but not in an open-loop pipe-flowing system. In such an experiment, ions of formed scales have a residence time of 30 minutes. Even the nuclei have been largely developed, but the crystal still has low surface energy and cannot adhere to the pipe surface and is then carried over by the flow.

To prepare the solution, calcium and carbonate reagents were diluted separately in 6 liters of distilled water. The solution was filtrated by a filter paper with $0.22 \mu \mathrm{m}$ micropores. Each solution was then stored in a covered vessel to avoid contamination from dust and other impurities. The material of the vessel was considered not to react with the solution and was strong enough to withstand the temperature at which the solution was heated. Oxalic acid $\left(\mathrm{C}_{2} \mathrm{H}_{4} \mathrm{O}_{2}\right)$ and formic acid $\left(\mathrm{CH}_{2} \mathrm{O}_{2}\right)$ additives were also diluted separately and added to the carbonate solution following the required concentration.

To correctly define the vibration parameter, the experiment was designed based on the observation of an industry powered by a diesel engine. The engine was run at $800 \mathrm{rpm}$ to operate a stone crusher machine, which was also equipped by a cooling tower water system erected 50 meters away from the engine. An electrical pump was used to drain water to the cooling tower of 20 meters height through a steel pipe of $160 \mathrm{~mm}$ diameter mounted around the diesel engine. Many mechanical types of equipment that could vibrate the pipe were also mounted around. When the machines operated, the pipe vibrated, and the vibration parameter was measured. A vibrometer was used to sense the vibration in 10 positions throughout the pipe. The mean score of those 10 data was calculated to define the research parameter as required. The real mean score was found as a vibration frequency of $5.95 \mathrm{~Hz}$; peak-to-peak displacement of $0.0038 \mathrm{~m}$, and acceleration of $1.9 \mathrm{~m} . \mathrm{s}^{-2}$. To enhance the influence of vibration on scale formation, vibration frequency was increased to $6.00 \mathrm{~Hz}$; displacement to $0.004 \mathrm{~m}$, and acceleration to $2 \mathrm{~m} . \mathrm{s}^{-2}$. The temperature of the pipe after the cooling process was measured and found at $45^{\circ} \mathrm{C}$. The data applied to operate the experimental rig is later discussed.

The vibration force potentially removes the crystals not strong enough to adhere to the inner pipe surface; this should be considered in the design for measuring the scale deposition. The removed scales must be included when measuring the scales deposited to avoid the bias in identifying the influence of vibration. To realize this, a strainer collects the removed scale deposition that is carried by the solution along the pipe. In this research, the scales of surface integration-controlled reaction adhered in a coupon. Coupon typically is a pipe made of copper, to which the scales adhere. Scales deposited in the coupon surface were then named as scale deposited in the coupon ( $\left.\mathrm{W}_{\text {coupon }}\right)$. Scales collected in the strainer could either be the scales of the diffusion-controlled reaction or scales removed from the pipe surfaces ${ }^{26}$. Because of the difficulty in distinguishing them, both scales are named as scale deposited in the strainer $\left(\mathrm{W}_{\text {strainer }}\right)$ for convenience. The net scale deposited ( $\left.\mathrm{W}_{\text {net }}\right)$ can be found through eq. (2).

$$
\mathrm{W}_{\text {net }}=\mathrm{W}_{\text {coupon }}+\mathrm{W}_{\text {strainer }}
$$

In this experiment, the scale deposition was examined at elevated temperatures of $35^{\circ} \mathrm{C}, 40^{\circ} \mathrm{C}$, and $45^{\circ} \mathrm{C}$; elevated vibration frequencies of $0.00 \mathrm{~Hz}, 3.00 \mathrm{~Hz}$, and $6.00 \mathrm{~Hz}$, and in the presence of oxalic and formic acid as much as $0.00 \mathrm{ppm}, 2.50 \mathrm{ppm}$, and $5.00 \mathrm{ppm}$.

\section{General Procedures}

A build in-house experimental rig operated by a computer program control was employed to conduct the experiment as shown schematically in Fig.-1. The rig consisted of two vessels containing $\mathrm{CaCl}_{2}$ and $\mathrm{Na}_{2} \mathrm{CO}_{3}$ solutions. To ensure the solutions were homogeneous, a stirrer was mounted in each vessel. The 
temperature was set by an electrical heater immersed in the solution and controlled by a sensor in a deviation of $\pm 0.5^{\circ} \mathrm{C}$. The solution in each vessel was drained by a dosing pump CHEM FEED Ca-92683 and set at a flow rate of $25 \mathrm{ml} / \mathrm{min}$. Both solutions reacted in the test pipe section.

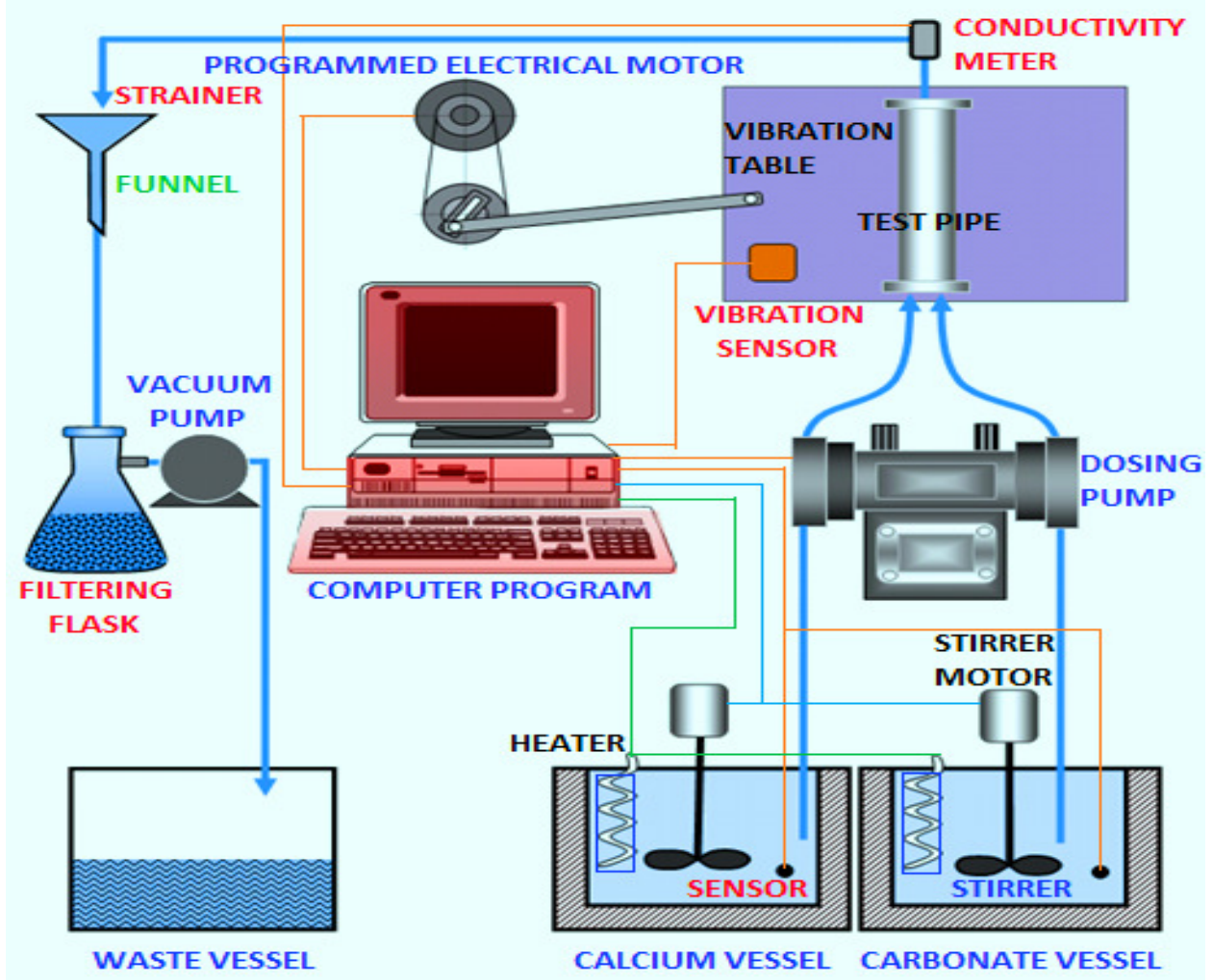

Fig.-1: Experimental rig

In the test pipe section, four pairs of coupons made of copper were inserted, in which scale was needed to form. The pipe was mounted at a table and vibrated mechanically by an electrical motor, which was set up by a computer program. The vibration was set at $0.00,3.00$, and $6.00 \mathrm{~Hz}$. Vibrometer Lutron VT-8204 was selected to record the vibration parameter such as peak-to-peak displacement $(\mathrm{m})$ and acceleration $\left(\mathrm{m} / \mathrm{s}^{2}-\mathrm{RMS}\right)$, and was shown in a computer program. A filter paper of $0.22 \mu \mathrm{m}$ was used to collect the scales brought by the flowing solution. A filtering flask and a vacuum pump were employed to help trap the crystals. The filter paper in the funnel was replaced every ten minutes to avoid from blockage.

Scales found in the coupon and strainer were dried in an electrical heater at $60^{\circ} \mathrm{C}$ for 6 hours. The scale was weighed in an Ohaus AR-2140 analytical balance when the scale still adhered in the coupon or strainer. The mass of scale in the coupon was calculated as the difference between the masses of the coupon with and without a scale. The mass of scale in the strainer was calculated by the difference between the masses of the strainer with and without a scale. Subsequently, the scale was kept in a dry cup after removed from the coupon or strainer and labeled as experiment parameter.

\section{Detection Methods}

The X-ray powder diffraction data for phase identification was collected using $\mathrm{Cu}-\mathrm{K} \alpha$ monochromated radiation in a conventional Bragg-Brentano parafocusing geometry (Rigaku Smart Lab, X-Ray Diffractometer). In this way, the scan parameters $10-100^{\circ} 2 \theta$ (0.020 steps; $\left.15 \mathrm{sec} / \mathrm{step}\right)$ were determined. The X-ray data collected were subsequently transferred into a PC-based search-match program (the MATCH Software) for matching crystalline phases. The peak positions and peak heights were matched against the entry powder diffraction data in the International Centre for Diffraction Data. The matched crystalline phases were then evaluated by the Rietveld method using FullProf-2k, software (version 3.30 ${ }^{27}$. The crystal structure model for Rietveld refinement has been obtained in the literature American 
RASĀYAN J. Chem.

Vol. 12 | No. 1 |192 - 204| January - March | 2019

Mineralogist crystal structure database $(\mathrm{AMCSD})^{28}$. The detailed discussion of the method is provided elsewhere. Cell parameters and scale factor were refined for determining the weight $\%$ levels of mineralogical phases. The weight levels in the phases were automatically calculated by the FullProf program.

The morphology of the precipitated scale was determined with an FEI Inspect S50 scanning electron microscope with an acceleration voltage of $20 \mathrm{kV}$. Images were taken using a Megaview III digital camera (EMSIS GmbH). Prior to elemental analysis, samples were mounted on a circular aluminum holder and finally sputtered with carbon.

The kinetics of $\mathrm{CaCO}_{3}$ scale formation was investigated using DSC analysis. The crystal component was analyzed in constant cooling rate using DSC 1 Mettler Toledo made in Switzerland. Initially, the crystal component was heated until $300^{\circ} \mathrm{C}$ at $50^{\circ} \mathrm{C} / \mathrm{min}$. Then, the temperature was held for some minutes to eliminate thermal history. Furthermore, the temperature was cooled by the air at the required rate. Every sample was analyzed five times at different cooling rates: $5{ }^{\circ} \mathrm{C} \cdot \mathrm{min}^{-1}, 10^{\circ} \mathrm{C} \cdot \mathrm{min}^{-1}, 15^{\circ} \mathrm{C} \cdot \mathrm{min}^{-1} ; 20{ }^{\circ} \mathrm{C} \cdot \mathrm{min}^{-}$ ${ }^{1}$, and $30{ }^{\circ} \mathrm{C} \cdot \mathrm{min}^{-1}$.

The dried precipitate was then analyzed using FTIR spectrometry to examine the influence of vibration and additives on $\mathrm{CaCO}_{3}$ scale formation. All spectra were recorded in bands from 400 to $4,000 \mathrm{~cm}^{-1}$, using IR-Prestige88 FTIR spectrometer, which can perform 200 scans/s with a spectral resolution of 2 $\mathrm{cm}^{-1}$. The spectra were recorded and stored using a spectroscopic software and were then graphed, as shown in Fig.-7.

\section{Scale Deposition}

\section{RESULTS AND DISCUSSION}

The scale deposition has been investigated in elevated temperature and vibration frequency. In the experiment, the scale deposited was measured in coupon $\left(\mathrm{W}_{\text {coupon }}\right)$ and strainer $\left(\mathrm{W}_{\text {strainer }}\right)$, and the net scale deposited $\left(\mathrm{W}_{\text {net }}\right)$ was calculated by the summation of both measured scales. For example, in the experiment of $0.00 \mathrm{~Hz}$ and $35^{\circ} \mathrm{C}$, the scale deposited in coupon ( $\mathrm{W}_{\text {coupon }}$ ) was $0.1423 \mathrm{~g}$, and the mass of scale deposited in a strainer $\left(\mathrm{W}_{\text {strainer }}\right)$ was $3.1788 \mathrm{~g}$. The summation of both measured scales resulted in the net scale deposition $\left(\mathrm{W}_{\mathrm{net}}=3.3211 \mathrm{~g}\right)$. The data of scale deposition are listed in Table 1 .

The influence of temperature and vibration frequency on scale deposition is investigated separately and simultaneously. To determine the correlation among temperature, vibration frequency, and scale deposition, the data is presented in a surface graph of Matlab, as depicted in Fig.-2. Line a-b depicts the correlation between temperature $(\mathrm{x})$ and scale deposited $(\mathrm{z})$. Line a-d depicts the correlation between vibration frequency (y) and scale deposited (z). Line a-c shows the synergy of the influence of temperature and vibration frequency on scale deposition.

The influence of temperature on $\mathrm{CaCO}_{3}$ scale deposition is shown in line $\mathrm{a}-\mathrm{b}$, which has a second order polynomial equation $z=0.0318 x^{2}-2.0492 x+36.078$. The equation shows that the influence of temperature on scale deposition is significant. Scales of surface integration-controlled reaction for unvibrated experiment were $0.0541 \mathrm{~g}$ and $0.1532 \mathrm{~g}$ for the reactions of $35^{\circ} \mathrm{C}$ and $45^{\circ} \mathrm{C}$, respectively. The increase in scale deposited is almost $280 \%$. The influence of temperature on scale deposition found in this research corresponds with the results of other studies. For example, Hoang also found that temperature increase surface integration between the crystals and pipe surface[6]. The data of this experiment also show that the scale deposition scales of diffusion-controlled reaction increased from $3.2670 \mathrm{~g}$ to $8.1453 \mathrm{~g}$ or by $250 \%$ as the temperature increased from $35^{\circ} \mathrm{C}$ to $45^{\circ} \mathrm{C}$. $\mathrm{CaCO}_{3}$ is only soluble in $13 \mathrm{mg} / \mathrm{liter}$ at $25^{\circ} \mathrm{C}$; in addition; its solubility is inversely proportional to the temperature, which accounts for such an increase in the mass of scale deposition ${ }^{29}$.

The increase in scale deposited under the influence of vibration is shown in the surface graph by line a-d, which has a second order equation $\mathrm{z}=0.0496 \mathrm{y}^{2}-0.0479 \mathrm{y}+3.32$. The equation shows that scale deposited increased significantly when the reaction was subjected to vibration. As seen in Table 1, the scale deposition increased for both surface integration-controlled reaction and diffusion-controlled reaction.

The difference between the unvibrated and vibrated experiments is mainly the hydrodynamic force caused by vibration. The hydrodynamic force in vibration frequency $6.00 \mathrm{~Hz}$ can be calculated based on the data sent by the vibration sensor. The sensor showed an acceleration (a) of $2 \mathrm{~m} / \mathrm{s}^{-2} \mathrm{RMS}$, displacement (s) of 
$0.004 \mathrm{~m}$ or $0.048 \mathrm{~m}$ every second. The mass $(\mathrm{m})$ of the solution in the pipe was $0.013976 \mathrm{~kg}$ or in 0.137 $\mathrm{N}$. The time ( $\mathrm{t})$ to produce $1 \mathrm{~mol}$ of $\mathrm{CaCO}_{3}=($ Molar weight $/$ mass of reaction product $) \times$ time in seconds. Therefore, $\mathrm{t}=(100 / 3.3211) \times(4$ hours $\times 3,600 \mathrm{~s} /$ hour $)=433,591 \mathrm{~s} / \mathrm{mol}$. To calculate the energy $(\mathrm{E})$ contributed by the vibration, formula from Chang is adopted, i.e. ${ }^{30}$ :

$\mathrm{E}=\mathrm{m} \times \mathrm{a} \times \mathrm{s} \times \mathrm{t}$

$\mathrm{E}=0.13976 \mathrm{~N} \times 2 \mathrm{~m} / \mathrm{s}^{-2} \times 0.048 \mathrm{~m} / \mathrm{s} \times 433,591 \mathrm{~s} / \mathrm{mol}$

$\mathrm{E}=5,817 \mathrm{~J} / \mathrm{mol}$ or $5.817 \mathrm{~kJ} / \mathrm{mol}$.

The energy contributed by the vibration $(5.817 \mathrm{~kJ} / \mathrm{mol})$ significantly affected the scale deposition, as the mass of scale deposition increased from $3.3211 \mathrm{~g}$ to $4.8205 \mathrm{~g}$ at a temperature of $35^{\circ} \mathrm{C}$ and vibration frequency of $6.00 \mathrm{~Hz}$. In this experiment, the scale deposition of $4.8205 \mathrm{~g}$ involves the product of the surface integration-controlled reaction, diffusion-controlled reaction, and removing scale.

Table-1: Scale Deposition in Elevated Temperature and Vibration Frequency

\begin{tabular}{ccccccc}
\hline Vibration & Temperature & \multicolumn{2}{c}{ Additives $(\mathrm{ppm})$} & $\mathrm{W}_{\text {coupon }}$ & $\mathrm{W}_{\text {strainer }}$ & $\begin{array}{c}\mathrm{W}_{\text {net }} \\
(\mathrm{Hz})\end{array}$ \\
\cline { 3 - 4 }$\left({ }^{\circ} \mathrm{C}\right)$ & $\begin{array}{c}\text { Oxalic } \\
\text { acid }\end{array}$ & $\begin{array}{c}\text { Formic } \\
\text { acid }\end{array}$ & $(\mathrm{g})$ & $(\mathrm{g})$ & $(\mathrm{g})$ \\
\hline 0.00 & 35 & & & 0.0541 & 3.2670 & 3.3211 \\
0.00 & 40 & & & 0.0872 & 4.9159 & 5.0031 \\
0.00 & 45 & & & 0.1302 & 8.1453 & 8.2755 \\
3.00 & 35 & & & 0.0726 & 3.5522 & 3.6248 \\
3.00 & 40 & & & 0.1182 & 5.2454 & 5.3936 \\
3.00 & 45 & & & 0.1684 & 7.9142 & 8.0826 \\
6.00 & 35 & & & 0.0931 & 4.7274 & 4.8205 \\
6.00 & 40 & & & 0.1406 & 6.5135 & 6.6541 \\
6.00 & 45 & & & 0.2144 & 10.4154 & 10.6298 \\
6.00 & 45 & 2.50 & & 0.1951 & 9.7843 & 10.0994 \\
6.00 & 45 & 5.00 & & 0.1865 & 9.0426 & 9.2476 \\
6.00 & 45 & & 2.50 & 0.1715 & 9.0576 & 9.4291 \\
6.00 & 45 & & 5.00 & 0.1508 & 7.7149 & 7.8655 \\
\hline
\end{tabular}

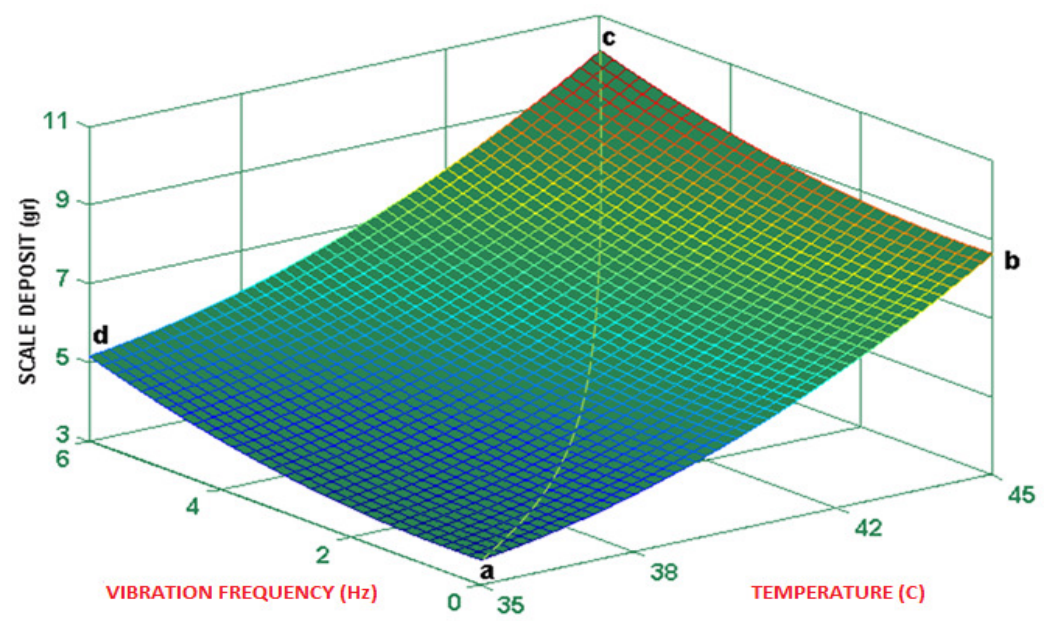

Fig.-2: Surface Graph of Temperature-Vibration Frequency-Scale Deposit

The mechanism of the influence of hydrodynamic force in scale formation was studied through its activation energy; this is discussed under DSC analysis. Vibration may not only affect scale formation in the magnitude of its hydrodynamic force. The manner of vibration that contributes force to the solution must be considered. The vibration that introduces hydrodynamic activity in the solution must be a vector of vibration force. When the vibration vector interacts with ionic vector, it would result in a new vector 
RASĀYAN J. Chem.

Vol. 12 | No. 1 |192 - 204| January - March | 2019

and affect scale formation. This may need further investigation. Synergistic influence of temperature and vibration on scale deposition is depicted in line a-c of the surface graph. The line has a second order equation $\mathrm{z}=0.1758 \mathrm{y}^{2}+0.1636 \mathrm{y}+3.3211$, where $\mathrm{z}$ is scale deposition in gram, and $\mathrm{y}$ is vibration frequency in Hz. Scale deposition increased drastically when elevated temperature and vibration frequency affected the experiment simultaneously, i.e., from $3.3211 \mathrm{~g}$ to $10.6298 \mathrm{~g}$ or by $325 \%$. The data agree with the research of Quddus and Hadhrami, which revealed that the increase in hydrodynamic force by stirring the solution from $100 \mathrm{rpm}$ to $1,000 \mathrm{rpm}$ could increase $\mathrm{CaCO}_{3}$ scale deposition from 1.392 $\mathrm{g} / \mathrm{m}^{2} \mathrm{~h}$ to $4.262 \mathrm{~g} / \mathrm{m}^{2} \mathrm{~h}^{14}$.

\section{Influence of Additives}

The influence of additives on scale deposition is depicted in Table-1. The respective applications of oxalic acid and formic acid additives show successful decrease the scale deposition. To assess the inhibition efficiency of these two additives, the method proposed by Kirboga can be applied in this research. According to Kirboga, the inhibition efficiency (IE) is calculated as eq. (3) ${ }^{31}$.

$$
\mathrm{IE}(\%)=\frac{\mathrm{Ro}-\mathrm{Ri}}{\mathrm{Ro}} \times 100
$$

Here, IE is inhibition efficiency in \%, Ro is scale deposition without additive, and Ri is scale deposition with the additive. The inhibition efficiency was calculated using eq. (3) and the scale deposition data listed in Table 1 for the experiments with additive and without additive (blank). The experiments in the presence of additives were conducted at a temperature of $45^{\circ} \mathrm{C}$ and a vibration frequency of $6.00 \mathrm{~Hz}$.

Oxalic acid additive in concentrations of 2.50 and $5.00 \mathrm{ppm}$ resulted in inhibition efficiencies of $5 \%$ and $13 \%$, respectively. Formic acid additive in concentrations of 2.50 and $5.00 \mathrm{ppm}$ resulted in inhibition efficiencies of $11 \%$ and $26 \%$, respectively. The use of formic acid resulted in higher efficiency than oxalic acid. This result is unusual since formic acid with only one carboxylate outperforms oxalic acid with two carboxylates. According to Hamzah, long-chain (of carboxylate) additives potentially cover up the lattice, a mechanism known as sequestration mechanism[32]. This result shows that the short-chain structure inhibitors do not operate by sequestration mechanism, as supposed by Hamzah, but may operate by other mechanisms. To reveal the phenomenon, severe analytical laboratory analyses were conducted i.e., DSC, SEM, XRD, and FTIR analyses.

\section{DSC analysis}

In this experiment, four samples (listed in Table 2) were characterized by DSC to calculate the activation energy of every reaction. Ozawa formula is shown in eq. (4) was used to calculate activation energy $^{33}$.

$\ln \beta=$ constant $-1.052\left[\mathrm{E}_{\mathrm{a}} / \mathrm{RT}_{\mathrm{p}}\right]$

Here, $\ln \beta$ is natural logarithm of temperature rate, $\mathrm{E}_{\mathrm{a}}$ is activation energy, $\mathrm{R}$ is ideal gas constant, and $\mathrm{T}_{\mathrm{p}}$ is peak temperature. To find the activation energy $E_{a}$, the gradient of the line $(m)$ was first obtained through the trendline equation from the plot of $\ln \beta$ against $1 / T_{p}$, and was then substituted to equation $E_{a}=$ $(\mathrm{m} \times \mathrm{R}) / 1.052$. The value of determinant $\left(\mathrm{R}^{2}\right)$ was close to 1 , indicating that the calculation has a high confidence level. The experiment data and the activation energy results are listed in Table- 2 .

Table-2 shows the magnitude of activation energy for the blank experiment was as high as $74.299 \mathrm{~kJ} / \mathrm{mol}$. This does not contradict the findings of other studies. Petrou and Terzidaki calculated $\mathrm{E}_{\mathrm{a}}$ of $\mathrm{CaCO}_{3}$ precipitation as $72.1 \mathrm{~kJ} / \mathrm{mol}^{34}$. Table 2 also shows that the activation energy was reduced to $70.517 \mathrm{~kJ} / \mathrm{mol}$ when the experiment was conducted under the vibration of $6 \mathrm{~Hz}$. The decline can be attributed to the energy contributed by the hydrodynamic force in the reaction process, and it was calculated as 5.817 $\mathrm{kJ} / \mathrm{mol}$ based on vibration sensor results. This shows that hydrodynamic force contributed activation energy to the reaction. This result enhances the results of Quddus and Hadhrami, who stated that hydrodynamic force decreased activation energy ${ }^{16}$. The use of oxalic and formic acid additives increased the activation energy to 74.915 and $77.297 \mathrm{~kJ} / \mathrm{mol}$, respectively. The increase of activation energy 
indicates that the acid affected the kinetics of $\mathrm{CaCO}_{3}$ scale formation by increasing the energy barrier of the reaction. As the energy barrier increase, it becomes more difficult for the product (or scale) to form, resulting in less scale deposition. The mechanism is discussed in FTIR analysis.

Table-2: Kinetics of $\mathrm{CaCO}_{3}$ Precipitation of Four Experiments

\begin{tabular}{|c|c|c|c|c|c|}
\hline Experiment & $\begin{array}{c}\text { Rate } \\
\left({ }^{\circ} \mathrm{C} / \mathrm{min}\right)\end{array}$ & $\begin{array}{l}\mathrm{T}_{\mathrm{p}} \\
\left({ }^{\circ} \mathrm{C}\right)\end{array}$ & Linearized equation & $\begin{array}{c}\text { Determinant } \\
\left(\mathrm{R}^{2}\right)\end{array}$ & $\begin{array}{c}\mathrm{E}_{\mathrm{act}} \\
\left(\mathrm{kJ} \cdot \mathrm{mol}^{-1}\right)\end{array}$ \\
\hline $0 \mathrm{~Hz}$ & 5 & 112.1 & $y=-8,936.7 x+17,40$ & 0.9920 & 74.299 \\
\hline \multirow{4}{*}{ Blank } & 10 & 120.8 & & & \\
\hline & 15 & 128.1 & & & \\
\hline & 20 & 132.8 & & & \\
\hline & 30 & 141.5 & & & \\
\hline $6 \mathrm{~Hz}$ & 5 & 113,3 & $y=-8,481.8 x+16.23$ & 0.9933 & 70.517 \\
\hline \multirow[t]{4}{*}{ Blank } & 10 & 124,1 & & & \\
\hline & 15 & 130,6 & & & \\
\hline & 20 & 136 & & & \\
\hline & 30 & 146 & & & \\
\hline $6 \mathrm{~Hz}, 5 \mathrm{ppm}$ & 5 & 114.1 & $y=-9,010.8 x+17.55$ & 0.9624 & 74.915 \\
\hline \multirow[t]{4}{*}{ Oxalic acid } & 10 & 125.1 & & & \\
\hline & 15 & 130.4 & & & \\
\hline & 20 & 135.8 & & & \\
\hline & 30 & 144 & & & \\
\hline $6 \mathrm{~Hz}, 5 \mathrm{ppm}$ & 5 & 114.2 & $y=-9,297.3 x+18.70$ & 0.9892 & 77.297 \\
\hline \multirow[t]{4}{*}{ Formic acid } & 10 & 124.3 & & & \\
\hline & 15 & 129.5 & & & \\
\hline & 20 & 134.8 & & & \\
\hline & 30 & 143.9 & & & \\
\hline
\end{tabular}

\section{Crystals Morphology}

$\mathrm{CaCO}_{3}$ crystals morphology was investigated after the crystals were characterized by SEM (FEI Inspect $\mathrm{S} 50$ ). To examine the influence of temperature, vibration, and additives on scale formation, crystals of blank-unvibrated, blank-vibrated, oxalic acid-vibrated, and formic acid vibrated experiments were characterized. Fig.-3a shows the morphology of the $\mathrm{CaCO}_{3}$ crystal of unvibrated-blank experiment at $45^{\circ} \mathrm{C}$. All the crystalline phases of anhydrateCaCO 3 , i.e.,vaterite, aragonite, and calcite, appeared proportionally. The crystals are shown in the normal

shape. Some vaterite phases began to transform to aragonite. The aragonite phase developed at over $40^{\circ} \mathrm{C}^{35,36}$. Meanwhile, Fig.-3b shows the morphology of the crystals from the blank-vibrated experiment at $6.00 \mathrm{~Hz}$. Aragonite appeared in fertile otherwise calcite and vaterite shows in slighter.
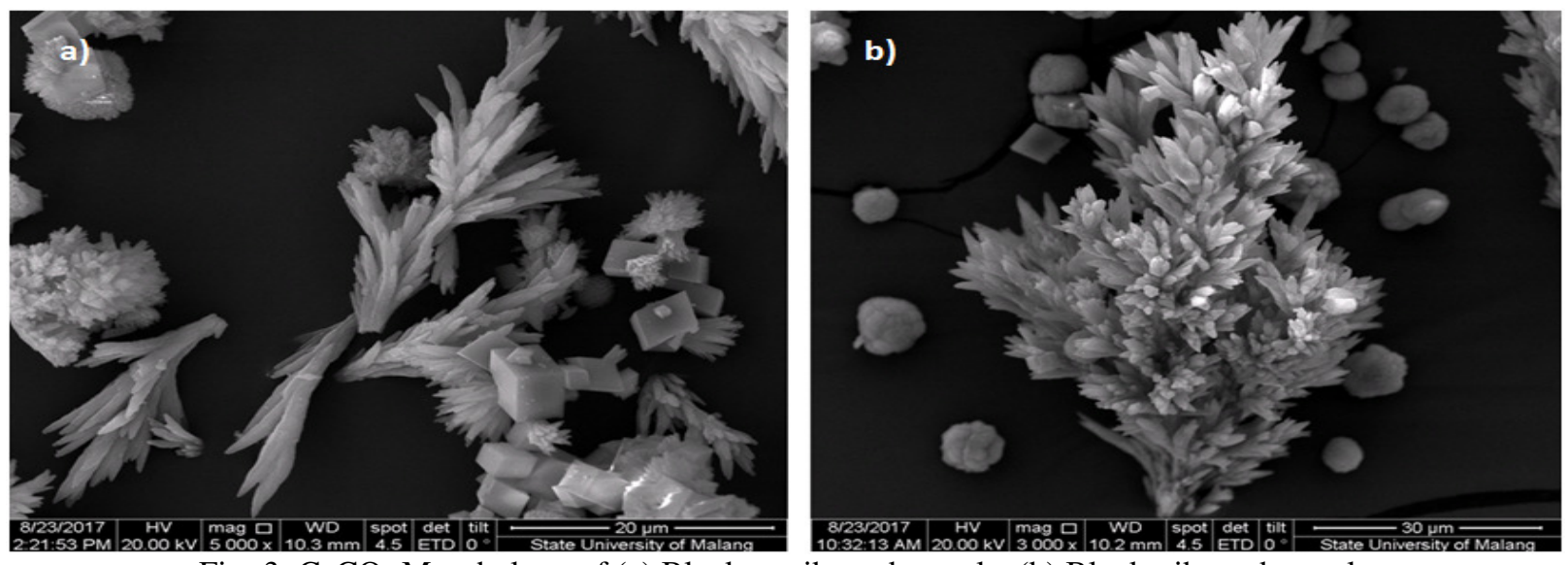

Fig.-3: $\mathrm{CaCO}_{3}$ Morphology of (a) Blank-unvibrated sample, (b) Blank-vibrated sample 
Aragonite needs higher energy to develop, and it began to develop only at a temperature of $40^{\circ} \mathrm{C}^{36}$. Aragonite was the main phase at this temperature (see XRD analysis); this does not correspond with the findings of other studies, which stated that aragonite predominate the phases when the temperature reached above $60^{\circ} \mathrm{C}^{35}$. This discrepancy could be caused by the hydrodynamic force contributed by vibration. The contributed energy $(5.817 \mathrm{~kJ} / \mathrm{mol})$ possibly overcame the high energy required by aragonite to develop in large amounts.
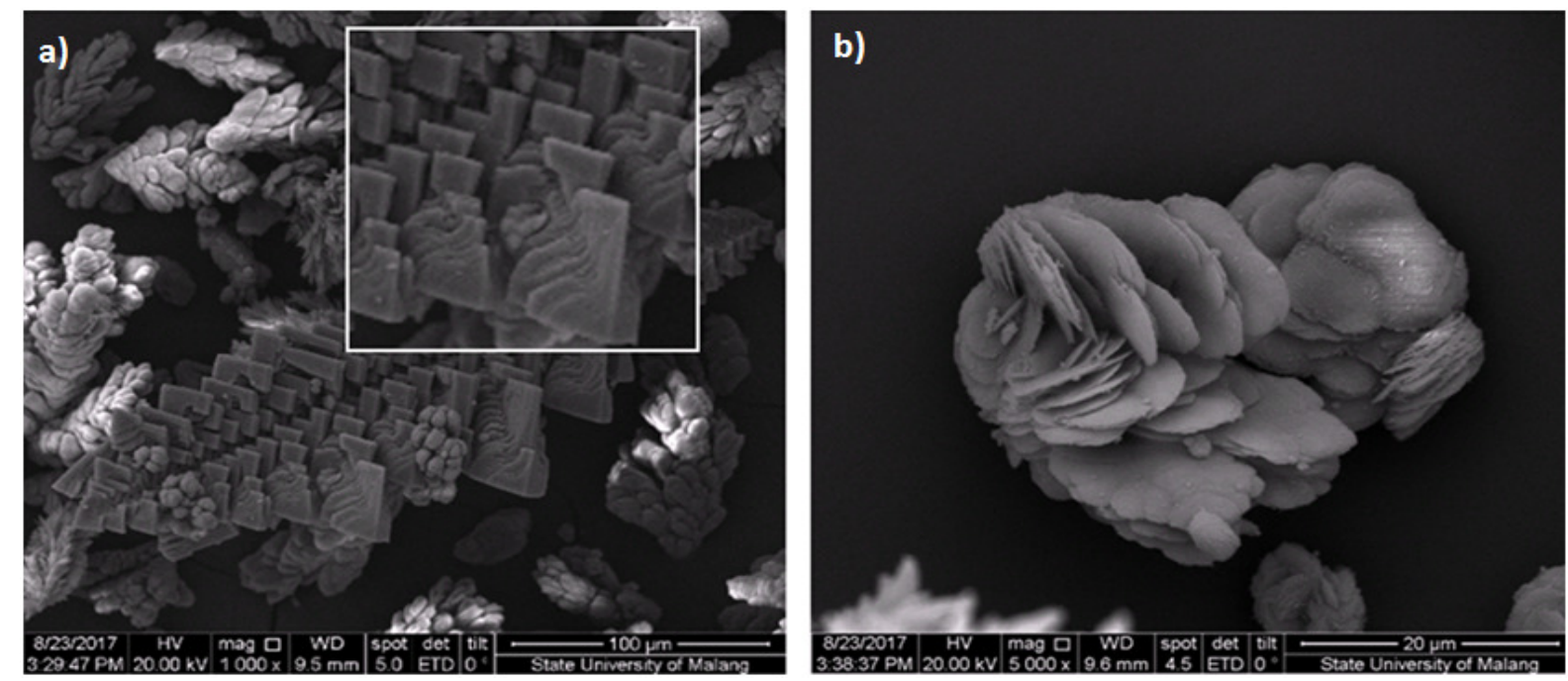

Fig.-4: $\mathrm{CaCO}_{3}$ Morphology of (a) Oxalic Acid-vibrated, (b) Formic Acid-vibrated Samples

Figure-4 shows sample crystals of oxalic acid- and formic acid-vibrated experiments conducted at a vibration frequency of $6.00 \mathrm{~Hz}$, temperature of $45^{\circ} \mathrm{C}$ and additives concentration of $5.00 \mathrm{ppm}$. Fig.-4a shows the morphology of the oxalic acid-vibrated experiment samples. Three phases of $\mathrm{CaCO}_{3}$ crystals exist in this experiment. Calcite developed unusually, as its morphology is unconventional. Its layers look as though chained and not separate each other.The peculiar characteristic is the direct transformation of vaterite into calcite as shown in the cropped box, and not via aragonite. This unusual feature in crystal growth is likely due to the addition of oxalic acid.

Fig.-4b shows the crystal produced by the reaction of $\mathrm{CaCO}_{3}$ under the influence $5.00 \mathrm{ppm}$ formic acid, the temperature at $45^{\circ} \mathrm{C}$, and vibration frequency in $6.00 \mathrm{~Hz}$. The polymorph shows peculiarity, but its edge, which has a hexagonal form, is still recognized. The normal hexagonal vaterite has been transformed into an unusual habit. This habit may be called hexagonal thin plate vaterite as the edge is hexagonal and physically thin like a plate. The polymorph almost has no geometry and is like a paper or thin plate. The transformation is possible because the carboxylic family has the potential to modify crystal habit, which crystal growth may undergo only in a certain plane, and result in a new habit ${ }^{37}$. Ukrainczyk also pointed that the addition chemical substances or foreign ions in the solution can modify the morphology and crystals size ${ }^{38}$.

\section{FTIR Analysis}

The graph depicted in Fig.-5 shows four lines in different colors. The blue and red lines show the spectra of the blank-unvibrated and blank-vibrated experiments, respectively. Meanwhile,the green and purple lines show the spectra of the oxalic acid-vibrated and formic acidvibrated experiments, respectively.

In the finger print region, the sample of blank- $0.00 \mathrm{~Hz}$ experiment shows that aragonite emerged in three peaks: $700.16 \mathrm{~cm}^{-1} ; 856.39 \mathrm{~cm}^{-1}$, and $875.68 \mathrm{~cm}^{-1}$ bands, which are assigned as the stretching modes of aragonite ${ }^{39,40}$. When the experiment affected by vibration $6.00 \mathrm{~Hz}$ (red line), the shoulder of $856.39 \mathrm{~cm}^{-1}$ split to two peaks $844.82 \mathrm{~cm}^{-1}$ and $854.47 \mathrm{~cm}^{-1}$ bands, which are assigned as aragonite absorption. This splitting peak indicates that the vibration promoted the scaling process occurring in higher dynamics. The split was also accompanied by the shifted peak of $875.68 \mathrm{~cm}^{-1}$ to lower band $873.70 \mathrm{~cm}^{-1}$ that assigned as the bending mode of aragonite. According to Badger rule, the lower band indicates that stretching and 
bending modes need lower energy ${ }^{40}$. The phenomenon indicates that aragonite developed easier when in the presence of vibration and agrees with the XRD data, in which the aragonite phase was the highest fraction.

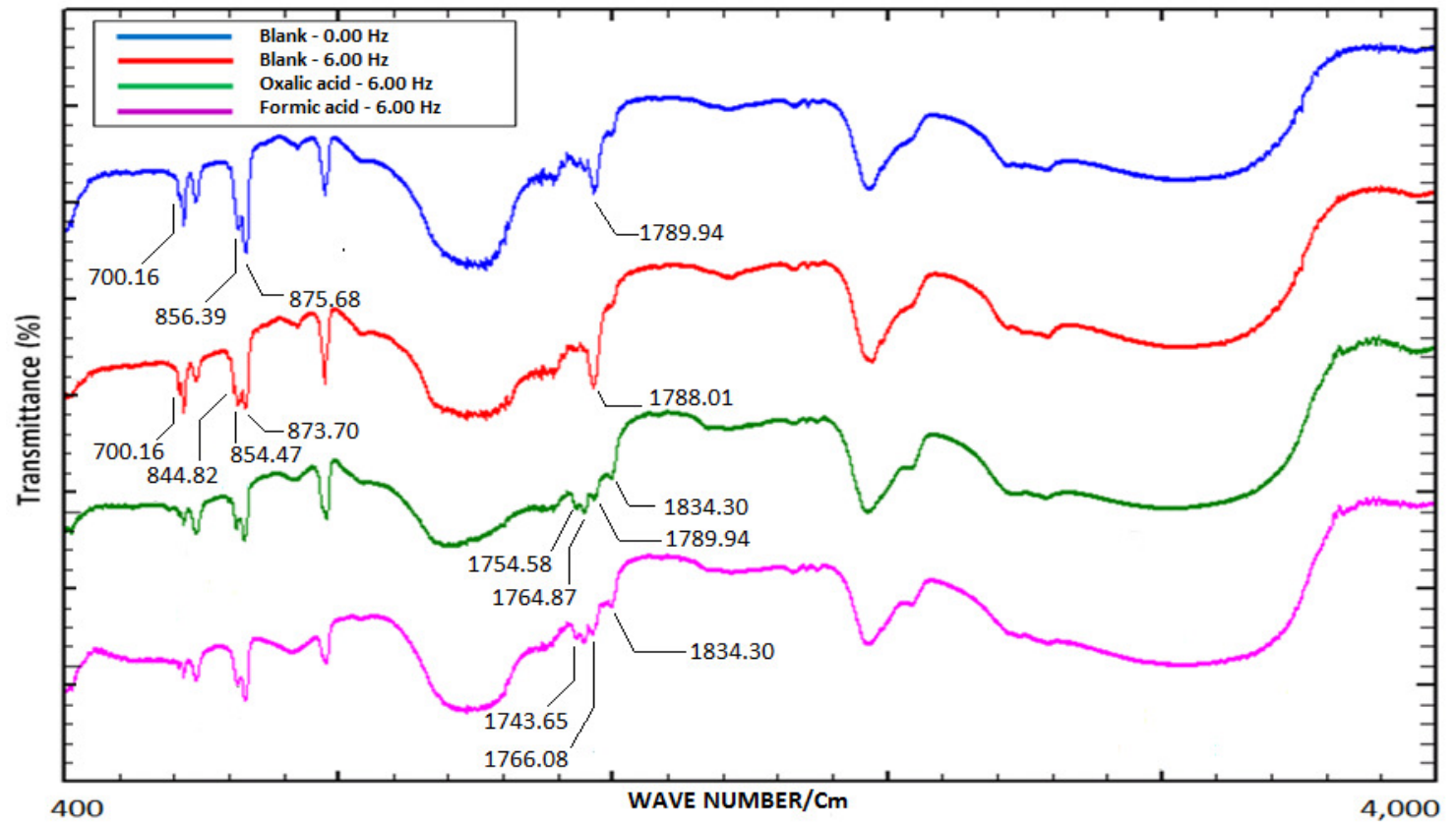

Fig.-5: FTIR Spectra of $\mathrm{CaCO}_{3}$ Scale Formation in the Presence of Vibration and Inhibitor

Spectrum in double atoms region (between $1,500 \mathrm{~cm}^{-1}$ and around $1,800 \mathrm{~cm}^{-1}$ ) shows a peak in 1,789.94 $\mathrm{cm}^{-1}$ when the experiment was conducted without vibration and additive. The peak is assigned as $\mathrm{C}-\mathrm{O}$ stretching vibration to provide carbonate ion from $\mathrm{Na}_{2} \mathrm{CO}_{3}$. When vibration was implemented to the experiment in $6.00 \mathrm{~Hz}$, the peak shifted to lower band $1,788.01 \mathrm{~cm}^{-1}$. Although the shift was small, it is enough to show that carbonate ion provided an easier and fairly assisted scale formation process. Therefore, the scale deposition is larger when the experiment is influenced by vibration.

In the experiment with additive oxalic acid and vibration in $6.00 \mathrm{~Hz}$, two peaks $1,754.58 \mathrm{~cm}^{-1}$ and $1,764.87 \mathrm{~cm}^{-1}$; they are assigned as $\mathrm{C}-\mathrm{O}$ stretching vibration of carboxyl or carbonyl from oxalic acid that successfully diffused in the crystals lattice. Those peaks affected the peak of $1,788.01 \mathrm{~cm}^{-1}$, which was then split to higher peaks of $1,789.94 \mathrm{~cm}^{-1}$ and $1,834.30 \mathrm{~cm}^{-1}$, and they are assigned as weak absorption of carbonate anions. In the experiment in the presence of formic acid and vibration of $6.00 \mathrm{~Hz}$, two peaks emerged i.e., $1,743.65 \mathrm{~cm}^{-1}$ and $1,766.08 \mathrm{~cm}^{-1}$, and are assigned as $\mathrm{C}-\mathrm{O}$ stretching vibration of carboxyl or carbonyl from formic acid. These peaks affected the peak of $1,788.01 \mathrm{~cm}^{-1}$ shifted to $1,834.30 \mathrm{~cm}^{-1}$, and it is assigned as weak absorption carbonate anions. The weaker and higher bands of the split and the shifted peaks of the two experiments involving additives indicate that the formation carbonate anions from $\mathrm{Na}_{2} \mathrm{CO}_{3}$ dissociation required higher energy. The results of FTIR analysis corresponds with that of DSC analysis. DSC analysis shows that the activation energy of the two experiments involving additives increases from $70.517 \mathrm{~kJ} / \mathrm{mol}$ (blank-6.00 Hz experiment) to $74.915 \mathrm{~kJ} / \mathrm{mol}$ (for oxalic acid-6.00 Hz experiment) and $77.297 \mathrm{~kJ} / \mathrm{mol}$ (for formic acid-6.00 Hz experiment). This shows that oxalic and formic acid additives successfully diffused into the lattice and retarded scale formation.

\section{Phases Identification}

Phases identification of dried precipitate has been well analyzed utilize FTIR spectrometer ${ }^{41}$. However, in this research, XRD analysis was operated to conduct the quantification. The raw data as xy file was plotted through WinPLOTR, a graphic tool for powder diffraction. Each spectrum was separated by the addition of a set of y line with up to 300 counts to ease interpretation, as shown in Fig.-6. The blue and red lines show the spectra of the blank-unvibrated and blank-vibrated experiments, respectively, and the green and purple lines show the spectra of oxalic acid-vibrated and formic acid-vibrated experiments, respectively. 
RASĀYAN J. Chem.

Vol. 12 | No. 1 |192 - 204| January - March | 2019

Fig.-6a shows the refinement results of XRD Rietveld methods for the sample of unvibrated experiment, providing that the intensity peaks of phases, which had been identified in the search-match program, clearly agree in the difference plot of the calculated and measured diffraction profiles. Consequently, all peaks could be identified and marked by their phases, i.e., $\mathrm{C}$ for calcite, $\mathrm{A}$ for aragonite, and $\mathrm{V}$ for vaterite (Fig.-6b).
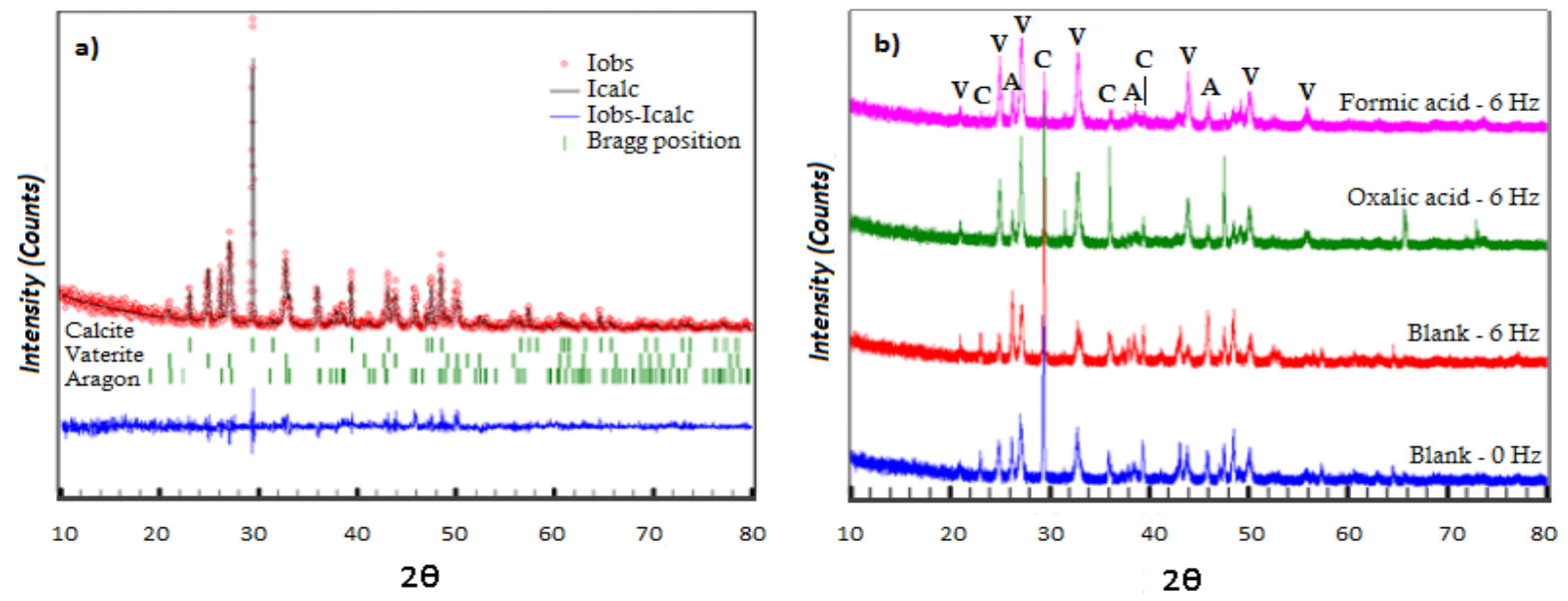

Fig.-6: (a) XRD Rietveld Plot of Refinement Results and (b) XRD Patterns of the Samples

The results of the quantitative analysis are listed in Table-3. Initially, the mass fractions of calcite, vaterite, and aragonite phases were $34.89 ; 43.03$ and $22.08 \mathrm{wt} . \%$. Under vibration, the fractions were altered to $26.00,28.00$, and $46.00 \mathrm{wt} . \%$. Unlike in the unvibrated experiment,aragonite had the highest fraction under the vibration of $6.00 \mathrm{~Hz}$. The data reveals that when the experiment is affected by vibration, the reaction exhibits higher dynamics, and aragonite predominates the phases. The XRD results agree with the previously discussed SEM and FTIR results.

Table-3: Crystals Phases Compositions of Four Experiments at $45^{\circ} \mathrm{C}$

\begin{tabular}{ccccc}
\hline \multirow{2}{*}{ No } & \multirow{2}{*}{ Experiment } & \multicolumn{3}{c}{ (wt.\%) } \\
\cline { 3 - 5 } & Blank sample, $0 \mathrm{~Hz}$ & Calcite & Aragonite & Vaterite \\
\hline 1 & Blank sample, $6 \mathrm{~Hz}$ & 34.89 & 22.08 & 43.03 \\
2 & Oxalic acid 10 ppm, 6 Hz & 23.00 & 46.00 & 28.00 \\
3 & Formic acid 10 ppm, 6 Hz & 7.18 & 15.69 & 60.67 \\
4 & & 21.69 & 71.13 \\
\hline
\end{tabular}

The experimental results for the use of additives in $6.00 \mathrm{~Hz}$ vibration show that vaterite increased from $26 \mathrm{wt} . \%$ to $60.67 \mathrm{wt} . \%$ and $71.13 \mathrm{wt} . \%$ for oxalic and formic acid additions, respectively. Considering the scale deposition, large amounts of vaterite phase may decrease the mass of scale deposition because vaterite is the least dense among all phases. The use of additives also stabilized the vaterite phase, as it did not transform, or only small amounts transformed to aragonite and calcite. The phenomenon was affected by the presence of inhibitor ions that diffused to the lattice and stabilized the phase (see FTIR analysis). This also agrees well with other research. Yang pointed out that the addition of inhibitor can slightly affect vaterite transformation to aragonite and calcite ${ }^{42}$. Wang also pointed out that calcite can be formed from the transformation of aragonite and vaterite in the absence of an inhibitor ${ }^{43}$.

\section{CONCLUSION}

In this study, $\mathrm{CaCO}_{3}$ scale formation in vibrating piping systems in the presence oxalic and formic acid was investigated, and information on the scaling behavior under the influences of temperature, vibration, and oxalic and formic acid additives was obtained. Scale deposition was examined under the synergistic influence of elevated temperature and vibration frequency. The results showed that the elevated temperature and vibration yielded a higher amount of scale deposition. The use of oxalic and formic acid 
RASĀYAN J. Chem.

Vol. 12 | No. 1 |192 - 204| January - March | 2019

in trace amounts successfully inhibited the scale formation, and formic acid performed better. SEM analysis showed morphology transformation from vaterite to calcite when the scaling process was subjected to vibration and additive oxalic acid. A new habit of hexagonal thin-plate vaterite polymorph was formed under vibration and formic acid additive. FTIR analysis also proved that vibration provided a hydrodynamic force that affected the scaling process in higher dynamics. Oxalic and formic acid additives have also been proven to be capable of successfully diffusing in $\mathrm{CaCO}_{3}$ lattice, consequently affecting reaction mechanism; fewer carbonate molecules are developed, and fewer scales are deposited.

\section{ACKNOWLEDGMENT}

This work was supported by the Ministry of Research Technology and Higher Education of the Republic of Indonesia, grant number: 345 15/UN7.5.1/PG/2017.

\section{REFERENCES}

1. A. Martinod, M. Euvrard, A. Foissy, and A. Neville, Desalination, 220, 1(2008), DOI:10.1016/j.desal.2007.01.039

2. Y. Tang, W. Yang, X. Yin, Y. Liu, P. Yin, and J. Wang, Desalination, 228, 1(2008), DOI: 10.1016/j.desal.2007.08.006

3. E. M. Flaten, M. Seiersten, and J. P. Andreassen, J. Cryst. Growth, 311, 13(2009), DOI: 10.1016/j.jcrysgro.2009.04.014

4. H. L. Yadav and A. Jamal, RASAYAN J. Chem.,11, 1 (2018), DOI:10.1016/j.jcrysgro.2009.04.014

5. K. Prasanna and R. Annadurai, RASAYAN J. Chem., 9, 2 (2016).

6. T. A. Hoang, H. M. Ang, and A. L. Rohl, Powder Technol., 179, 1(2007). DOI: $10.1016 /$ j.powtec.2006.11.013

7. G. M. F.Alimi, M.Tlili, M.B.Amor, C.Gabrielli, Adv. Mater. Res., 206(2007), DOI: 10.4028/www.scientific.net/AMR.554-556.649

8. C. Y. Tai, C. K. Wu, and M. C. Chang, Chem. Eng. Sci., 63, 23 (2008), DOI: 10.1016/j.ces.2008.08.004

9. D. Laskovski, P. Stevenson, and K. P. Galvin, Chem. Eng. Res. Des., 87, 12 (2009), DOI: 10.1016/j.cherd.2009.05.002

10. F. Liang and B. Wen, Acta Mech. Solida Sin., 24, 6 (2011), DOI: 10.1016/S0894-9166(11)60047-5

11. B. S. Kim, Y. K. Kim, and J. Choi, J. Mech. Sci. Technol., 22,12 (2008), DOI: 10.1007/s12206-0080505-7

12. B. G. Sinir and D. D. Demir, Eur. J. Mech. B/Fluids, 52(2015), DOI: 10.1016/j.euromechflu.2015.01.005

13. X. Han, W. Lin, Y. Tang, C. Zhao, and K. Sammut, Comput. Fluids, 110 (2015), DOI:10.1016/j.compfluid.2014.12.022

14. C. Ruiz-Cárcel, V. H. Jaramillo, D. Mba, J. R. Ottewill, and Y. Cao, Mech. Syst. Signal Process., 66-67, 699(2016).

15. C. Andrew, H. Mark, and N. Ioan, J. Hydrodyn., 27, 1(2015), DOI: 10.1016/S1001-6058(15)604541

16. A. Quddus and L. M. Al-Hadhrami, Desalination, 246, 1(2009), DOI: 10.1016/j.desal.2008.11.005

17. N. Wada, K. Kanamura, and T. Umegaki, J. Colloid Interface Sci., 233, 1(2001), DOI: 10.1006/jcis.2000.7215

18. A Ersen, A. Smith, and T. Chotard, J. Mater. Sci., 41(21), 7210(2006), DOI:10.1007/s10853-0060918-6

19. C. Tzotzi, T. Pahiadaki, S. G. Yiantsios, A. J. Karabelas, and N. Andritsos, J. Memb. Sci., 296, 1(2007), DOI: $10.1016 / \mathrm{j} . \mathrm{memsci.2007.03.031}$

20. N. N. Al-Mutairi, F. Abdul Aleem, and M. I. Al-Ahmad, Desalin. Water Treat., 10, 39(2009), DOI: 10.5004/dwt.2009.732

21. F. He, K. K. Sirkar, and J. Gilron, J. Memb. Sci., 345, 1(2009), DOI: 10.1016/j.memsci.2009.08.021

22. W. D. Callister, 2007, Materials Science and Engineering An Introduction, 7th ed. John Wiley \& Sons, Inc, USA. 
RASĀYAN J. Chem.

Vol. 12 | No. 1 |192 - 204| January - March | 2019

23. H. Koch and W. Haaf, Org. Synth., 44 (1964), DOI: 10.15227/orgsyn.044.0001

24. Y. Marcus, Biophys. Chem., 124, 3 (2006), DOI: 10.1016/j.bpc.2006.04.013

25. E. Mugnaioli et al., Angew. Chemie - Int. Ed., 51, 28 (2012), DOI: 10.1002/anie.201200845

26. B. Bansal, X. D. Chen, and H. Müller-Steinhagen, Chem. Eng. Process. Process Intensif., 47, 8 (2008), DOI: 10.1016/j.cep.2007.03.016

27. J.Rodriguez-Carvajal, "Program Fullprof 2k." 1937.

28. P. Y. Mahieux, J. E. Aubert, M. Cyr, M. Coutand, and B. Husson, Waste Manag., 30, 3 (2010), DOI: 10.1016/j.wasman.2009.10.023

29. K. Palanisamy and V. K. Subramanian, Powder Technol., 294 (2016), DOI: 10.1016/j.powtec.2016.02.036

30. R.Chang and J.Overby, 2011, General Chemistry, 6th ed. New York: McGraw-Hill.

31. S. Kirboga and M. Öner, Powder Technol., 249 (2013), DOI: 10.1016/j.powtec.2013.07.015

32. A. A. Al-Hamzah, C. P. East, W. O. S. Doherty, and C. M. Fellows, Desalination, 338, 1 (2014), DOI: $10.1016 / \mathrm{j}$. desal.2014.01.020

33. M. J. Starink, Int. Mater. Rev., 49, 3(2004), DOI: $10.1179 / 095066004225010532$

34. A. L. Petrou and A. Terzidaki, Chem. Geol., 381 (2014), DOI: 10.1016/j.chemgeo.2014.05.018

35. D. B. Trushina, T. V. Bukreeva, M. V. Kovalchuk, and M. N. Antipina, Mater. Sci. Eng. C, 45 (2015), DOI: $10.1016 / \mathrm{j} . \mathrm{msec} .2014 .04 .050$

36. J. Peña et al., Desalination, 254, 1(2010), DOI: 10.1016/j.desal.2009.12.011

37. Z. Mao and J. Huang, J. Solid State Chem., 180, 2 (2007), DOI: 10.1016/j.jssc.2006.11.002

38. M. Ukrainczyk, J. Kontrec, V. Babić-Ivančić, L. Brečević, and D. Kralj, Powder Technol., 171, 3 (2007), DOI: $10.1016 /$ j.powtec.2006.10.046

39. F. A. Andersen and L. Brecevic, Acta Chem. Scand., 45, 1018(1991), DOI: 10.3891/acta.chem.scand.45-1018

40. R.M.Badger, J. Chem. Phys., 2, 128 (1934).

41. N. Patel and A. Singh, Rasayan J. Chem.,8, 2 (2015).

42. X. Yang, G. Xu, Y. Chen, F. Wang, H. Mao, and W. Sui, J. Cryst. Growth, 311,21 (2009), DOI:10.1016/j.jcrysgro.2009.08.025

43. C. Wang, S. Li, and T. Li, Desalination, 249, 1 (2009), DOI:10.1016/j.desal.2009.06.006

[RJC-5055/2018] 